\title{
Optimization of Recuperative System in Rotary Furnace for Minimization of Elemental Loss during Melting
}

\author{
Sylvester Olanrewaju Omole ${ }^{1}$, Raymond Taiwo Oluyori ${ }^{2}$ \\ ${ }^{1}$ Metallurgical and Materials Engineering Department, Federal University of Technology, Akure, Nigeria \\ ${ }^{2}$ Metallurgical Engineering Department, School of Engineering, Kogi State Polytechnic, \\ Itakpe Campus, Okene, Nigeria \\ Email: sylvesteromole@yahoo.com, soomole@futa.edu.ng
}

Received 30 August 2014; revised 6 October 2014; accepted 31 October 2014

Academic Editor: Nader El-Bagoury, Central Metallurgical R \& D Institute, Cairo, Egypt

Copyright (C) 2014 by authors and Scientific Research Publishing Inc.

This work is licensed under the Creative Commons Attribution International License (CC BY). http://creativecommons.org/licenses/by/4.0/

(c) (i) Open Access

\begin{abstract}
Two rotary furnaces of different construction model were used for the research work. One has no recuperating system and the second one has recuperating system. $60 \mathrm{~kg}$ of grey cast iron scrap was charged into each of the furnaces at different time, after preheating the furnaces for $\mathbf{4 0}$ minutes. $0.5 \mathrm{~kg}$ graphite and $0.2 \mathrm{~kg}$ ferrosilicon were charged along with the scrap. The theoretical charge calculations have the composition of the melt as $4.0 \%$ carbon and $2.0 \%$ silicon. Charges in the furnaces were heated to obtain molten metal suitable for casting at $1350^{\circ} \mathrm{C}$. The content of the furnaces was tapped three times after the attainment of $1350^{\circ} \mathrm{C}$ with 15 minutes interval between each tapping. Optical light emission spectrometer was used to analyze the resulting composition of the tapped samples. For type A furnace (without recuperation), sample $A$ has its carbon and silicon contents reduced compared to expected value by $25.5 \%$ and $10.8 \%$, sample B reduced by $29 \%$ and $13.4 \%$ and sample $C$ reduced by $32 \%$ and $17.0 \%$ respectively. In Type $B$ furnace (with recuperation), sample $D$ has its carbon and silicon contents reduced by $12.2 \%$ and $7.3 \%$, Sample $E$ reduced by $13.0 \%$ and $8.0 \%$ and sample $F$ reduced by $13.9 \%$ and $8.9 \%$ respectively.
\end{abstract}

\section{Keywords}

Carbon, Silicon, Casting, Recuperation, Carbon Equivalent Value, Melting and Charges 


\section{Introduction}

Rotary furnace is one of the suitable furnaces for the production of irons. However, conventional furnaces for producing ductile iron are: induction furnaces of different types, electric arc furnace and cupola furnace. Due to difficulty in operating air furnaces producing a low carbon, malleable cast iron and as a result of wasteful in fuel, rotary furnace was designed [1]. Rotary furnaces have cylindrical barrel which revolves completely at the rate of about one revolution per minute. Their capacity ranges from few kilograms to several tonnes, there is a single burner at one end of the barrel; they are fired by oil or pulverized coal. High temperature flame melts and superheats the charge in the furnace barrel. The waste gases that pass out at the other end of the barrel can be directed through a series of recuperation tubes on their way to the chimney [1]. This can be use to pre heat the incoming cold air in order to increase the efficiency of the furnace [1].

Founding of metal often referred to as casting is the process of producing a solid metal from liquid state. The cast article is brought into final shape by allowing the molten metal to fill the mould and solidify in the mould cavity of suitable shape [2]. A wide range of components from domestic use to space vehicles are produced by founding process [3].

Cast iron is the most commonly cast ferrous metal; it is made up of iron, along with carbon, silicon, phosphorus, manganese and sulphur. Carbon has a powerful effect on the structure and properties of iron. The solubility limit of carbon in iron at eutectic temperature of $1130^{\circ} \mathrm{C}$ is $2.0 \%$. The material will be graded as steel if the carbon content is lower than this limit, whereas anything above this limit is considered as cast iron [4]. The properties of grey iron depend on the size, amount and distribution of the graphite flakes and on the structure of the metal matrix. These, in turn, depend on the chemical composition of the iron, in particular its carbon and silicon content, and also on processing variables such as method of melting, inoculation practice and the cooling rate of the casting [5]. The three constituents of cast iron which most affect strength and hardness are total carbon, silicon and phosphorus. An index known as the carbon equivalent value combines the effect of these elements.

$$
\text { Carbon Equivalent Value }(\mathrm{CEV})=\% \mathrm{C}+\frac{(\% \mathrm{Si}+\% \mathrm{P})}{3}
$$

where $\mathrm{C}=$ Total $\%$ carbon. Si and $\mathrm{P}$ are $\%$ of silicon and phosphorus respectively.

\section{Background of the Study}

Furnaces such as induction furnace and electric arc furnace, where adequate cleanliness and control of melt is achieved are not easily available in some developing countries such as Nigeria, due to their cost, maintenance and mostly the challenge of power supply. Therefore, there is the need to adopt and utilize the available rotary furnace for research in the production of irons. However, this furnace (rotary furnace) has drawback in terms of elemental loss in the composition of the metal produced. This seems not to be clearly known to the users of the furnace the reasons for the loss, and after production bothers not about the resulting composition. It is important to know the way the loss in composition and the magnitude of the loss occur, as well as the management required of the furnace. The furnace without recuperating system is shown in Figure 1, and it is characterized by wastage of hot flue gases which are allowed to pass through the chimney and to the surrounding environment. The recuperating system involves the means of directing the hot flue gases through series of tubes where the hot flue gases is utilized for pre-heating the incoming air and fuel. Such is obtainable in Figure 2. However, the two furnaces in Figure 1 and Figure 2 are the same both in construction and operation only with the inclusion of recuperating system in that of Figure 2. The use of rotary furnace will contribute to the industrial growth and improvement of the economy of developing nations, as there will be technological breakthrough in the spare parts production for automobile and other industries [6].

The aim of this research work is to investigate the behavior of rotary furnace in terms of oxidation of the major elements present in iron during melting, also to study the effects of recuperating system on the elemental loss and efficiency of the furnace. Many users of rotary furnace have projected only about $10 \%$ elemental losses in rotary furnace which the research seeks to find out. This has made composition control difficult during the use of the furnace. Meanwhile, the composition of melt for ductile iron production is an important force to achieving correct nodules in the iron [7] [8]. This is no exception for rotary furnace if the furnace is to be used for melting ductile iron base metal.

Type B furnace contained the same components with type A' furnace (as labeled above) with only the inclusion of bent exhaust on trolley, which is lined with refractory material for the purpose of transmitting heat into 


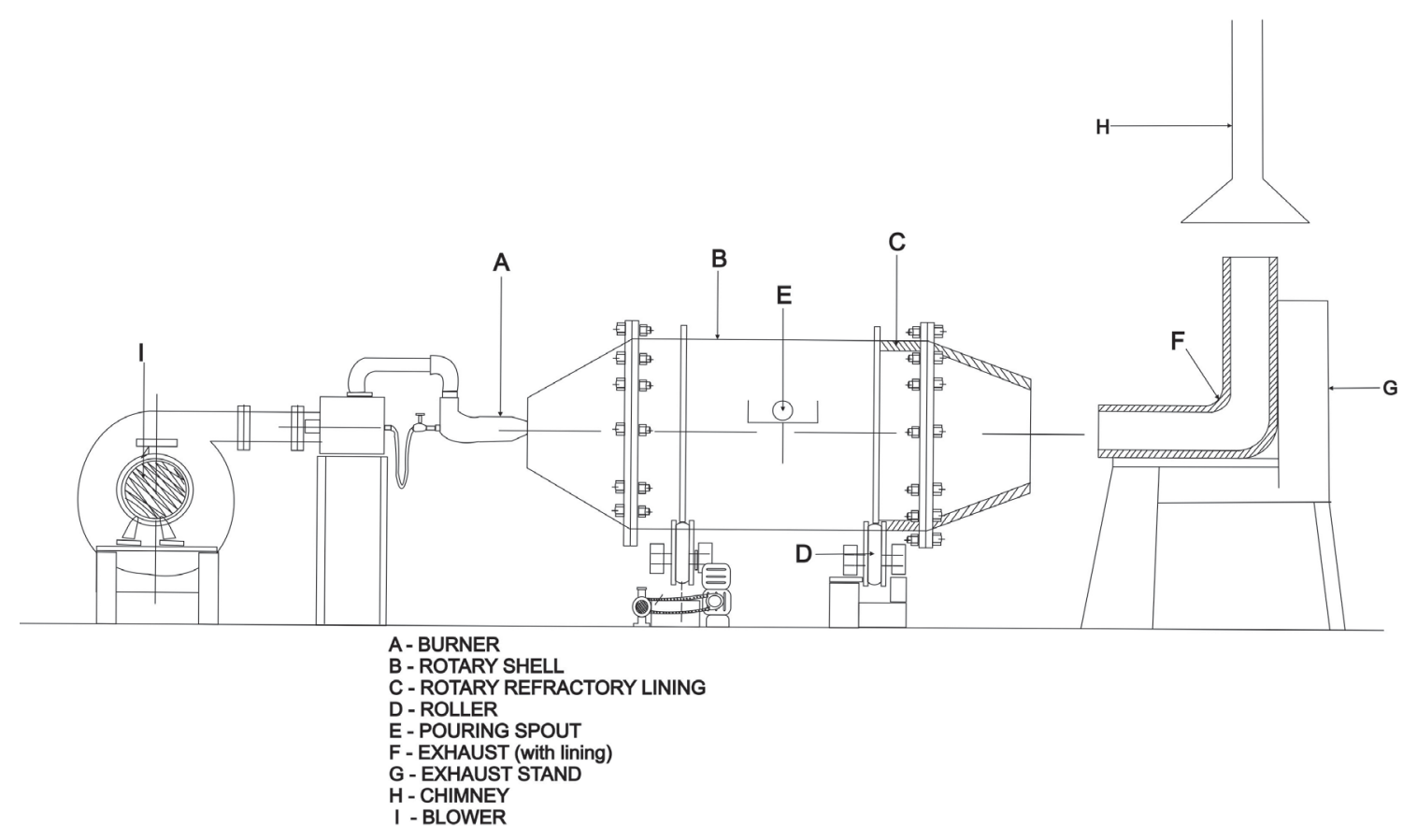

Figure 1. Layout diagram of type (A) rotary furnace (without recuperating system).

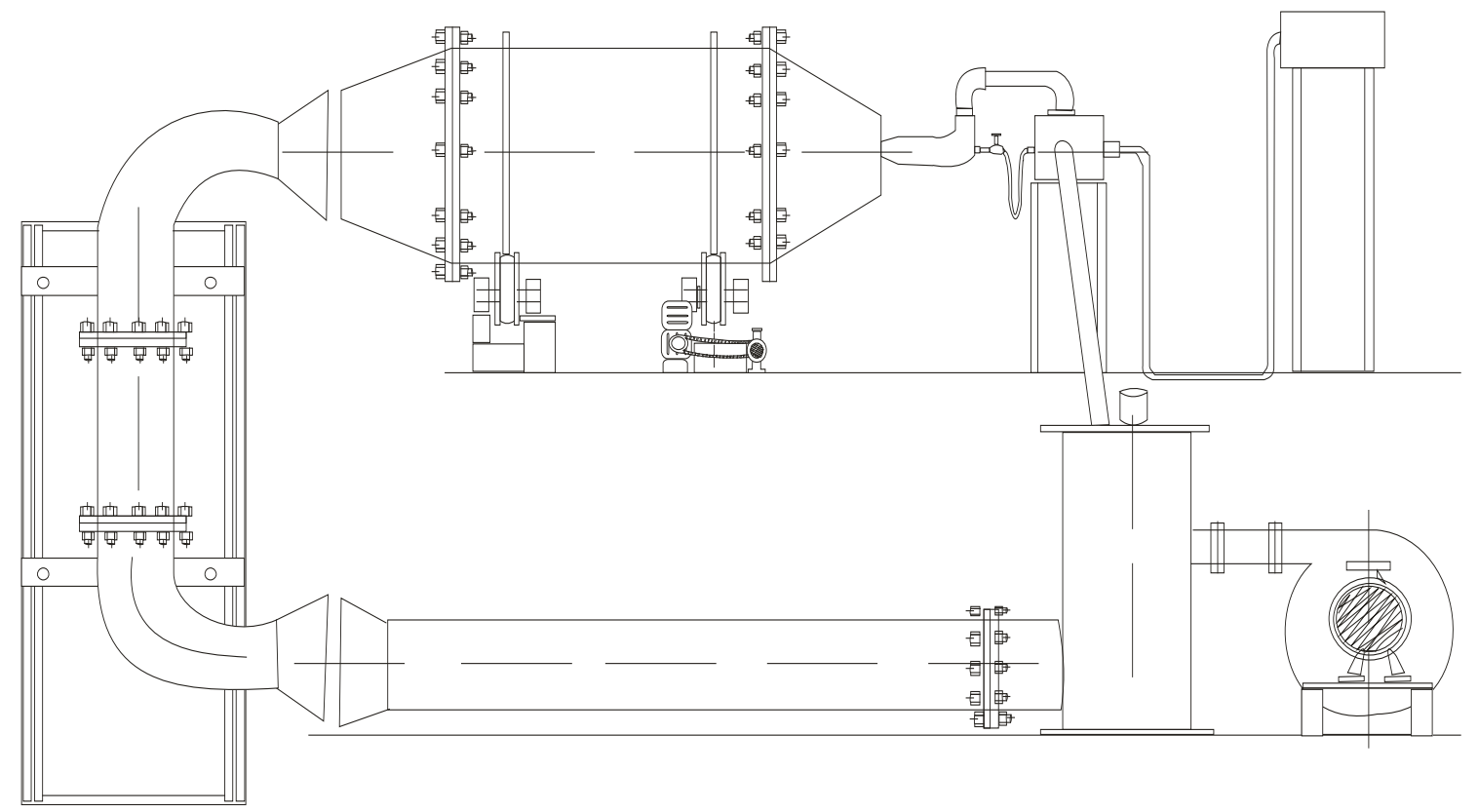

Figure 2. Layout diagram of type (B) rotary furnace (comprising of recuperating system).

pre-heat tank. The interior of the pre-heat tank contained air passage component which is heated by hot flue gas. The heated air then returned to heat the oil at the point of atomization.

\section{Methodology}

\subsection{Melting with Rotary Furnace}

The rotary furnaces were preheated for 40 minutes without any charge material in them. This will help to in- 
crease the temperature of the furnaces atmosphere above room temperature thereby making the melting faster. $60 \mathrm{~kg}$ of grey cast iron scrap of known chemical composition was charged into each of the rotary furnaces along with $0.5 \mathrm{~kg}$ graphite and $0.2 \mathrm{~kg}$ ferrosilicon at different time. The charges were prepared to have a theoretical carbon and silicon composition of $4.0 \%$ and $2.0 \%$ respectively, after an assumption of $10 \%$ elemental loss.

They were heated in the furnaces with diesel oil as fuel; air from blower is in contact with the oil and is atomized into the furnaces for burning. The furnaces were rotated at an angle $180^{\circ}$ after the first 25 minutes of firing. This is to enhance even distribution of heat on the charged materials in the furnace. As soon as the scrap began to melt at a temperature of about $1150^{\circ} \mathrm{C}-1200^{\circ} \mathrm{C}$, full rotation of the furnace was put on for homogenization of the melt. The molten metal attains temperature of $1350^{\circ} \mathrm{C}$ after about 1 hour 30 minutes when type $\mathrm{A}^{\prime}$ furnace was used, and 1 hour 10 minutes when type B' furnace was used.

\subsection{Casting of Metal}

Green sand moulds were prepared with a cylindrical pattern of diameter $20 \mathrm{~mm}$ from which tests can be conducted. The molten metal was tapped inside $15 \mathrm{~kg}$ capacity refractory lined ladle, at three different times for each of the furnaces. Prepared green sand moulds were cast with the molten metal. Time interval between each tapped metal was 15 minutes. The castings were allowed to solidify in the mould to room temperature, and were removed, fettled and cleaned. Type A furnace castings are labeled A, B and C while type B castings are labeled $\mathrm{D}, \mathrm{E}$ and $\mathrm{F}$ in the order of casting.

\subsection{Composition Analysis}

A sample was cut from each casting (castings A to F). They were grinded with emery paper of 400 grits. This was done to obtain smooth and flat surface samples. Spark was made on three different portions on each sample using optical light emission spectroscopy. The average composition of the samples was recorded.

\section{Results}

Results of composition analysis of the iron produced with the two furnaces are presented in Table 1 and Table 2.

\section{Efficiency}

There was an improvement in the efficiency of the furnace when type B' furnace was used. Type A' furnace has an efficiency of $3.12 \%$ while type B' furnace has efficiency of $4.08 \%$. The detailed calculation of the efficiencies is shown at Appendix.

\section{Discussion}

The oxidation noticed from the above results was due to the mode of operation of rotary furnace in which the

Table 1. Elemental characterization of iron produced with type A’ furnace.

\begin{tabular}{ccccccc}
\hline Sample & \%C & \%Si & \%P & \%C Loss & \%Si Loss & 10.8 \\
A & 2.98 & 1.73 & 0.075 & 25.5 & 29 & 13.4 \\
B & 2.84 & 1.68 & 0.064 & 32 & 17.0 \\
C & 2.72 & 1.61 & 0.068 & 3.42 & 3.28 \\
\hline
\end{tabular}

Table 2. Elemental characterization of iron produced with type B furnace.

\begin{tabular}{ccccccr}
\hline Sample & \%C & \%Si & \%P & \%C Loss & \%Si Loss & CEV \\
\hline D & 3.51 & 1.85 & 0.072 & 12.2 & 1.3 & 8.0 \\
E & 3.48 & 1.84 & 0.074 & 13.0 & 13.9 & 8.9 \\
F & 3.44 & 1.82 & 0.069 & 4.07 \\
\hline
\end{tabular}


fuel, charges and the products of combustion are all in contact. The rate of percentage loss of elements through oxidation in the furnace is also dependents on the time spent to complete melting and tapping. Meanwhile, more time has to be given to the melt during super heating in the furnace, in order to attain the desired fluidity and temperature before tapping. It was observed that the carbon oxidized more than the silicon, because the graphite which is a source of carbon easily supports combustion, this is why coke can be used as fuel for melting in furnaces. Therefore the rate of oxidation of carbon in the melt is higher. This analysis helps to assess the elemental loss that takes place during melting with the rotary furnaces. Meanwhile, silicon loss can be remedied by addition of ferrosilicon via ladle process. This will serve as a means of inoculation as well as increasing the composition of the desired element (silicon) in the melt.

It was discovered that the carbon equivalent value of the castings decreases downward as carbon and silicon oxidizes in the melt as shown in Table 1 and Table 2. Carbon and silicon are major elements contributing to CEV. Initially the iron was prepared to produce hypereutectic iron (CEV above 4.3\%); the result obtained shows that all the castings produced are hypoeutectic iron (CEV below 4.3\%). As CEV decreases it becomes increasingly difficult to produce sound castings, so also the fluidity of the metal reduces down. Carbon equivalent value is an important parameter that speaks much about the fluidity of metal as well as strength and hardness i.e. mechanical properties.

CEV has increased considerably when type B furnace was used; this can be seen in Table 2 and is due to reduction in oxidation of carbon and silicon. This will definitely bring an improvement in the fluidity as well as expected improvement in mechanical properties. The utilization of the hot flue gases that was a waste in type A' furnace has helped in increasing the kinetic of the fuel. This in turn made the combustion to be completed with increased calorific value of the fuel. It was observed in this furnace that the time spent to attain the targeted temperature of $1350^{\circ} \mathrm{C}$ was shorter by 20 minutes (i.e. within $1 \mathrm{hr} .10$ minutes as compared to $1 \mathrm{hr} .30$ minutes in type A' furnace). The efficiency of the two furnaces was very small due to the capacity of the furnaces (100 kg) compared to the fuel consumption as well as loss of heat from various sources from the furnaces. However with the utilization of recuperating system in type B rotary furnace, the efficiency has been enhanced from $3.12 \%$ to 4.08\% as calculated at the Appendix.

\section{Conclusion}

From the results obtained, even when the two furnaces used indicated that the rate of elemental loss during processing of material in rotary furnace is a time dependent phenomenon. However, the rate of elemental loss was minimized when type B furnace with recuperating system was used. Also the efficiency of the furnace has increased (from 3\% to 4\% when type B furnace was used). Therefore, efficiency of rotary furnace can be enhanced through the collection of hot flue gases for preheating the air and fuel. This is one major essence of a recuperating system. Maintaining optimum performance for the variables that are needed to obtain high efficiency in the furnace will help reduce the time of processing in the furnace. The variables are: blower with enough blowing capacity, fuel with high calorific value and utilization of the hot flue gases for preheating the fuel and air.

\section{Recommendations}

It is recommended that higher quantity of graphite be added into charge calculation prepared by considering not less than $30 \%$ loss in the re-carburizer also, as it will help to minimize the rate of loss of carbon. Inoculation is highly recommended. It will make up for the loss of silicon in the furnace which will contribute to the increase in the value of CEV.

\section{References}

[1] Agarwal, R.L., Banga, T.R. and Nanghnani, T. (1981) Foundry Engineering. Khanna Publishers India, New Delhi, 150-280.

[2] Steve, H. (1996) Metal Casting: Appropriate Technology in the Small Foundry. Intermediate Technology Publications, London, 54-65.

[3] Masoud, Z. and Seyyed, M.A.B. (2010) Fracture Characteristics of Austempered Spheroidal Graphite Aluminium Cast Irons. Journal of Iron and Steel Research International, 17, 31-35. 
[4] Jain, P.L. (1990) Principles of Foundry Technology. 3rd Edition, Tata McGraw-Hill Publishing Company Limited, Noida.

[5] Brown, J.R. (1994) Foseco Foundry Man Handbook. Butterworth-Heinemann, Oxford, 221-232.

[6] Akinlabi, O. and Omole, S.O. (2011) Evaluation of Ductile Iron Produced using Rotary Furnace with Variable Compositions of Magnesium Addition. International Journal of Science and Advanced Technology (IJSAT), 1, 276-282.

[7] Di Cocco, V., Lacoviello, F. and Cavallini, M. (2010) Damaging Micro Mechanisms Characterisation of a Ferritic Ductile Cast Iron. Journal of Engineering Fracture Mechanics, 77, 2-3.

[8] Murat, B. and Seckin, I.A. (2009) Successive Boronizing and Austempering for GGG-40 Grade Ductile Iron. Journal of Iron and Steel Research International, 16, 50-54.

[9] (2005) Bureau of Energy Efficiency, pp. 97-103. www.pcra.orgT

\section{Appendix}

\section{1) Calculation of Efficiency of the two Furnaces used}

According to the Bureau of Energy Efficiency [9], the efficiency of oil furnaces can be judged by measuring the amount of fuel needed per unit weight of material.

$$
\text { Thermal Efficiency of furnace }=\frac{\text { Heat in the Stock }(\text { heat output })}{\text { Heat in the fuel consumed for heating the furnace }}
$$

Quantity of heat imparted (Q) (heat output) on the stock can be found from

$\mathrm{Q}=\mathrm{M} \times \mathrm{C}_{\mathrm{p}}\left(\mathrm{t}_{1}-\mathrm{t}_{2}\right)$ where

$\mathrm{Q}=$ Quantity of heat of stock in $\mathrm{k}$ Cal.

$\mathrm{M}=$ weight of the stock in $\mathrm{kg}$

$\mathrm{C}_{\mathrm{p}}=$ mean specific heat of stock in $\mathrm{k} \mathrm{Cal} / \mathrm{kg} \cdot{ }^{\circ} \mathrm{C}$

$\mathrm{t}_{1}=$ final temperature of stock desired, ${ }^{\circ} \mathrm{C}$

$\mathrm{t}_{2}=$ Initial temperature of the stock before it enters the furnace, ${ }^{\circ} \mathrm{C}$

For Type A furnace (without recuperating system)

Average fuel consumed $/$ hour $=55 \mathrm{litres} / \mathrm{hr}$

Mean specific heat of iron $=0.12 \mathrm{k} \mathrm{Cal} / \mathrm{kg} \cdot{ }^{\circ} \mathrm{C}$

Total mass of the stock (furnace capacity) $=100 \mathrm{~kg}$

$\mathrm{t}_{1}=1350^{\circ} \mathrm{C}$

$\mathrm{t}_{2}=35^{\circ} \mathrm{C}$

Specific gravity of oil $=0.92$

Gross calorific value $(\mathrm{GCV})$ of oil $=10000 \mathrm{k} \mathrm{Cal} / \mathrm{kg}$

Average fuel consumed by the furnace $=55$ litres $/ \mathrm{hr} .=55 \times 0.92=50.6 \mathrm{~kg} / \mathrm{hr}$

Heat output $=\mathrm{M} \mathrm{C}_{\mathrm{p}}\left(\mathrm{t}_{\mathrm{i}}-\mathrm{t}_{2}\right)=100 \times 0.12(1350-35)=15,780 \mathrm{kCal}$

$$
\text { Efficiency }=\frac{\text { Heat in the Stock (heat output })}{\text { Heat in the fuel consumed for heating the furnace }}
$$

Heat in the fuel consumed for heating the furnace (heat input) $=50.6 \times 10,000$

$$
\text { Efficiency }=\frac{15,780 \times 100}{50.6 \times 10000}=3.12 \%
$$

For Type B furnace (with recuperating system)

Average fuel consumed $=42$ litres $/ \mathrm{hr}=42 \times 0.92=38.64 \mathrm{~kg} / \mathrm{hr}$

Heat output $=100 \times 0.12(1315)=15780 \mathrm{k} \mathrm{Cal}$

Heat in the fuel consumed for heating the furnace $=38.64 \times 10000$ 


$$
\text { Efficiency }=\frac{15,780 \times 100}{38.64 \times 10000}=4.08 \%
$$

2) Carbon Equivalent Value Calculation for iron produced with Type A' furnace

$$
\mathrm{CEV}=\% \mathrm{C}+\frac{(\% \mathrm{Si}+\% \mathrm{P})}{3}
$$

Theoretical CEV for the prepared melt $=4.0+\frac{(2.0+0.088)}{3}=4.67$

CEV for sample $\mathrm{A}=2.98+\frac{(1.73+0.075)}{3}=3.58$

CEV for sample B $=2.84+\frac{(1.68+0.064)}{3}=3.42$

CEV for sample $\mathrm{C}=2.72+\frac{(1.61+0.068)}{3}=3.28$

3) Carbon Equivalent Value Calculation for iron produced with Type B furnace

$$
\mathrm{CEV}=\% \mathrm{C}+\frac{(\% \mathrm{Si}+\% \mathrm{P})}{3}
$$

CEV for sample D $=3.51+\frac{(1.85+0.072)}{3}=4.15$

CEV for sample $\mathrm{E}=3.48+\frac{(1.84+0.074)}{3}=4.12$

CEV for sample $F=3.44+\frac{(1.82+0.069)}{3}=4.07$ 
Scientific Research Publishing (SCIRP) is one of the largest Open Access journal publishers. It is currently publishing more than 200 open access, online, peer-reviewed journals covering a wide range of academic disciplines. SCIRP serves the worldwide academic communities and contributes to the progress and application of science with its publication.

Other selected journals from SCIRP are listed as below. Submit your manuscript to us via either submit@scirp.org or Online Submission Portal.
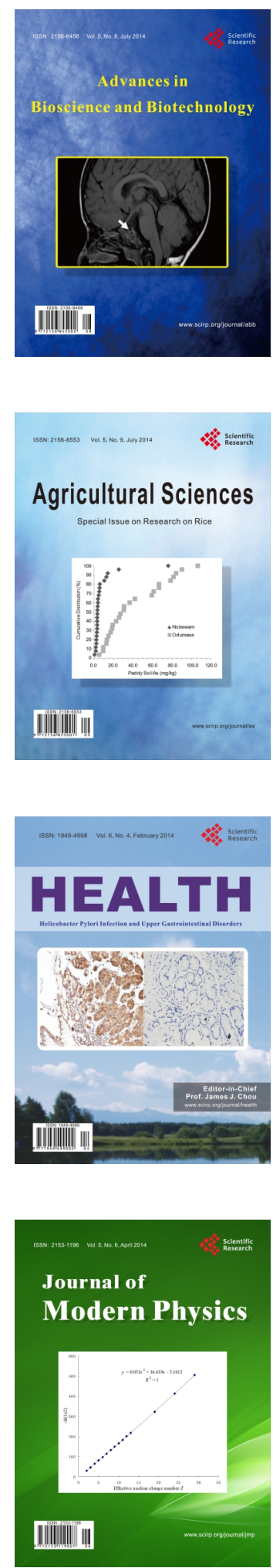
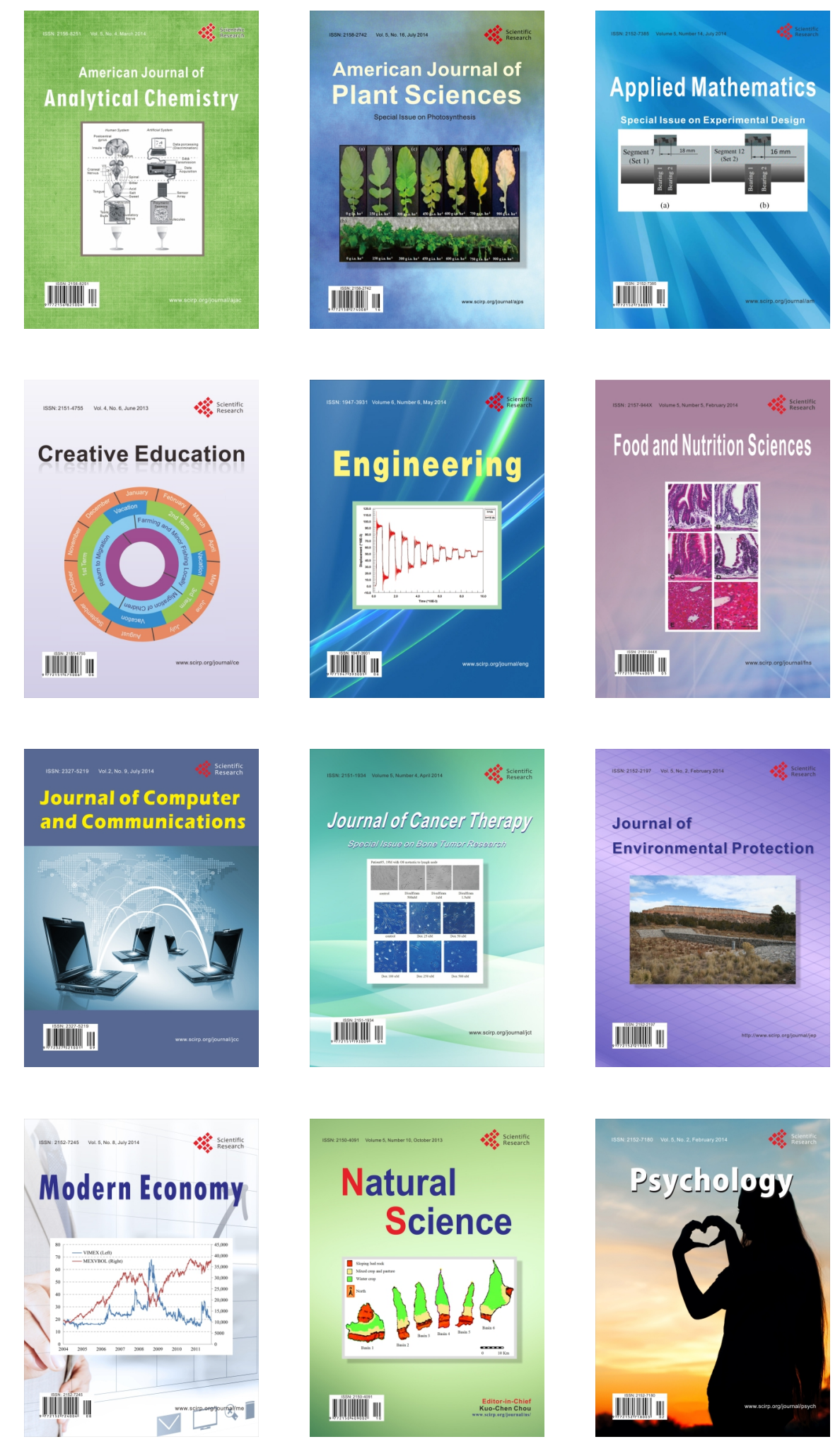